\title{
Optimization of Anti-reflection Coating for Improving the Performance of GaAs Solar Cell
}

\author{
Ashwini Joshi Thosar ${ }^{1}$, Manoj Thosar ${ }^{2^{*}}$ and R. K. Khanna ${ }^{3}$ \\ 'Department of Electrical Engg., Poornima University, Jaipur, India; \\ 2Department of Physics, Vivekananda Institute of Technology - East, VIT- campus, \\ Jaipur, India; labhesh9@gmail.com, \\ ${ }^{3}$ Department of Physics, Vivekananda Global University, VIT- campus, Jaipur,India;
}

\begin{abstract}
The objective of this work is to reduce the front surface reflectivity of the GaAs solar cell by depositing AR-coating of appropriate thickness and refractive index material. We use $\mathrm{MgO}$ and $\mathrm{ZnO}$ film and optimize their thickness for minimum reflectivity. Results indicate that the reflectivity is reduced up to $4 \%$ for $\mathrm{MgO}$ film and $2 \%$ for $\mathrm{ZnO}$ film at solar spectrum wavelength range from $550 \mathrm{~nm}$ to $650 \mathrm{~nm}$. The external efficiency of GaAs solar cell with AR-coating is increased by 31.53\% and $33.09 \%$ for $\mathrm{MgO}$ and $\mathrm{ZnO}$ film respectively.
\end{abstract}

Keywords: AM1.5D Spectrum, Anti-reflection Coating, External Efficiency, Fresnel Reflection, Interference of Light

\section{Introduction}

The performance of photovoltaic solar cell is determined in terms of Internal Quantum Efficiency (IQE) and external efficiency. The difference between these two efficiencies is quite large even for good quality solar cells. The modern technology of thin film device fabrication is capable of fabricating good quality solar cell with greater than $80 \%$ internal quantum efficiency. The overall efficiency of solar cell is reckoned in terms of external efficiency. The reported maximum value of external efficiency for $\mathrm{Si}$ solar cell is about $25 \%{ }^{1}$ and for GaAs solar cell is about $38 \%{ }^{2}$. This large difference between IQE and external efficiency is due to the poor light entering capacity of the solar cell structure. The light entering capacity is degraded by the Fresnel reflection. The phenomenon of Fresnel reflection occurs when light passes through the interface of two medium of different refractive index as shown in Figure 1.

The reflected intensity of light due to Fresnel reflection is depends on the refractive index difference of two materials and calculated by equ. 1 .

$$
I_{R}=\left[n_{2}-n_{1}\right]^{2} /\left[n_{2}+n_{1}\right]^{2}
$$

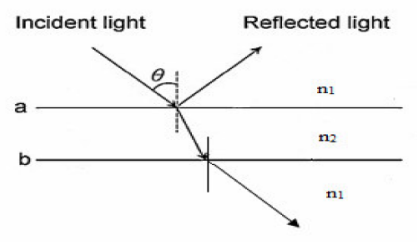

Figure 1. Fresnel reflection.

For GaAs solar cell, about $30 \%^{3}$ optical power is reflected from the front surface of the solar cell structure, which reduces the external efficiency of solar cell. To reduce, Fresnel reflection at the front surface of the solar cell, we use another optical phenomenon known as "Interference of light in thin film".

We have a material slab of refractive index $n$, on which we deposit AR-coating of material thickness $d$ and refractive index $n_{f}$ and expect that the light rays $R_{3}$ and $\mathrm{R}_{5}$ interferes destructively and transfer their energy inside the slab as shown in Figure 2.

The required thickness and refractive index of the AR-coating is given by equations (2) and (3) $)^{4,5}$

$$
\mathrm{d}=\lambda /\left(4 \times \mathrm{n}_{\mathrm{f}}\right)
$$

${ }^{*}$ Author for correspondence 


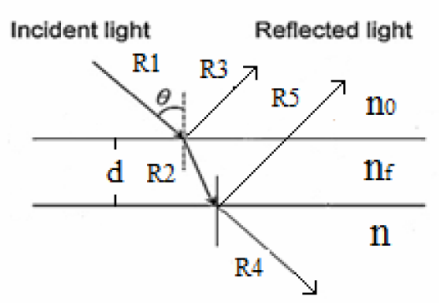

Figure 2. Basic principle of AR-coating.

$$
\mathrm{n}_{\mathrm{f}}=\sqrt{ }\left(\mathrm{n} \times \mathrm{n}_{0}\right)
$$

where, $\lambda$ is the wavelength of light and $n_{0}$ is the refractive index of the air.

In this paper, we optimize the thickness of AR-Coating for $\mathrm{GaAs}$ solar cell. Various techniques can be used to deposit AR-coating, the Chemical Vapor Deposition (CVD), spray, spin-on or screen printing. The spin-on is the simplest technique which is very efficient and does not need expensive equipment ${ }^{4,6,7}$. However this method can be used only on smooth, polished surfaces. For textured surface, the thickness of the AR- coating deposited by the spin-on method becomes uneven. Another method - Plasma Enhanced Chemical Vapor Deposition (PECVD) is more expensive, but it enables the deposition of layers with very good parameters - very uniform and of controlled thickness.

$\mathrm{ZnO}$ and $\mathrm{MgO}$ both are the well known II-VI semiconductor materials. Its energy band gaps are $3.3 \mathrm{eV}$ and $7.8 \mathrm{eV}$ respectively ${ }^{8,9} . \mathrm{ZnO}$ and $\mathrm{MgO}$ films are transparent for all solar radiations above the wavelength $0.37 \mu \mathrm{m}$ and $0.15 \mu \mathrm{m}$ respectively. The fabrication technology for both the materials is commercially available and both the materials have high radiation tolerance capacity at large temperature ${ }^{10}$. Therefore $\mathrm{ZnO}$ and $\mathrm{MgO}$ are the suitable materials for AR-coating of GaAs solar cell.

These AR-coatings may be extensively used for reflectivity modulation in various optical and optoelectronic components based on GaAs material. These include AntiReflection (AR) and High-Reflection (HR) coatings on broad band optical amplifiers and lasers ${ }^{11}$, AR-coating on lenses of camera and telescope ${ }^{12}$, and fabrication of polarizing beam splitters ${ }^{13}$ and various optical filters.

\section{Methodology}

We choose a simple homo-junction structure of photovoltaic solar cell. The list of parameters used in GaAs homo-junction solar cell simulation is given in Table 1 .
We assume that the solar radiations are incident at the top surface of the $\mathrm{n}$ - region and we have considered that there is no surface charge on the top and bottom surfaces of the device. We are taking ohmic contacts of resistance $20 \Omega$ and assuming that all the internal shunt element parameters are nil. The solar cell structure with out and with AR-coating is shown in Figure 3.

The excitation parameters used for simulation is shown in Table 2 and the materials used for AR-coating with their refractive index is listed in Table 3.

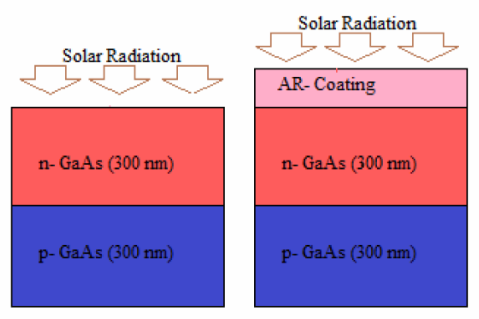

Figure 3. Solar cell structure with out and with ARcoating.

Table 1. List of Parameters used in solar cell simulation

\begin{tabular}{lll}
\hline S. No. Name of parameter & Value \\
\hline 1. & Device area & $100 \mathrm{~cm}^{2}$ \\
2. & Thickness of p- region & $300 \mathrm{~nm}$ \\
3. & Thickness of n-region & $300 \mathrm{~nm}$ \\
4. & Carrier mobility & from internal model of PC1D \\
5. & Dielectric constant & $13.18^{14}$ \\
6. & Energy band gap & $1.424 \mathrm{eV}^{14}$ \\
7. & Intrinsic concentration at $2.25 \times 10^{6} \mathrm{~cm}^{-314}$ \\
& 300 K & \\
8. & Refractive Index & $3.6{ }^{15,16}$ \\
9. & Absorption Coefficient & from internal model of PC1D \\
10. & Free carrier absorption & from internal model of PC1D \\
11. & Bulk Recombination $\left(\tau_{\mathrm{n}}\right)$ & $1000 \mu \mathrm{s}^{17}$ \\
12. & Bulk Recombination $\left(\tau_{\mathrm{p}}\right)$ & $1000 \mu \mathrm{s}^{17}$ \\
13. & p- type background & $1 \times 10^{18} \mathrm{~cm}^{-3}$ \\
& doping & \\
14. & n- type background & $1 \times 10^{18} \mathrm{~cm}^{-3}$ \\
& doping & \\
\hline
\end{tabular}

Table 2. List of excitation parameters

\begin{tabular}{lll}
\hline S. No. & Name of parameter & Value \\
\hline 1. & Excitation mode & Transient \\
2. & Temperature & $300 \mathrm{~K}$ \\
3. & Primary light source & AM1.5D spectrum \\
4. & Wavelength range & $300 \mathrm{~nm}$ to $1200 \mathrm{~nm}$ \\
\hline
\end{tabular}


Table 3. AR-coating material with their refractive index

\begin{tabular}{llc}
\hline S. No. & Material & Refractive Index \\
\hline 1. & $\mathrm{ZnO}$ & $1.95^{18}$ \\
2. & $\mathrm{MgO}$ & $1.72^{18}$ \\
\hline
\end{tabular}

\section{Results and Discussion}

By using parameters listed in Table 1 and Table 2, we perform the simulation of GaAs homo-junction solar cell without AR-coating, through PC1D (version 5.9) photovoltaic simulator and get the following results mentioned in the figures. Figure 4 shows the energy band diagram of GaAs homo-junction solar cell. Figures 5 and 6 shows the electric field and charge density distribution in depletion region of the solar cell and Figure 7 shows the carrier density distribution in entire solar cell structure. Figure 8 shows the base voltage verses current \& power curve of solar cell without AR-coating. Graph indicates that the fill factor of this solar cell is $82 \%$ with the values of open circuit voltage is 0.45 volts and short circuit current is 1.537 amps. The external efficiency of solar cell is $34.4 \%$.

To increase the extraction efficiency of GaAs solar cell we place the AR-coating of material listed in Table 3,

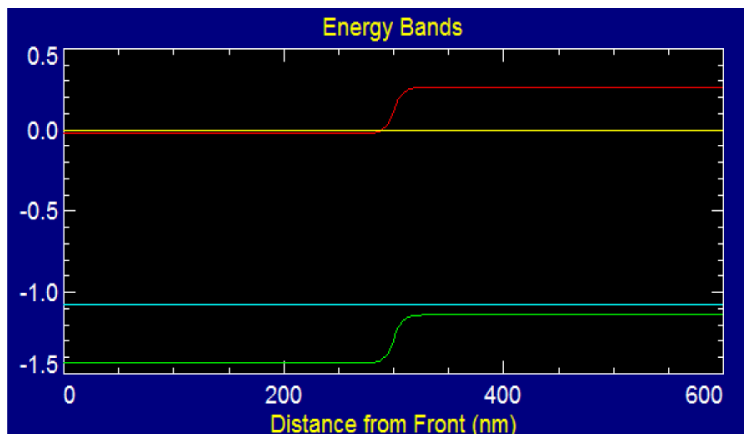

Figure 4. Energy band diagram of GaAs solar cell.

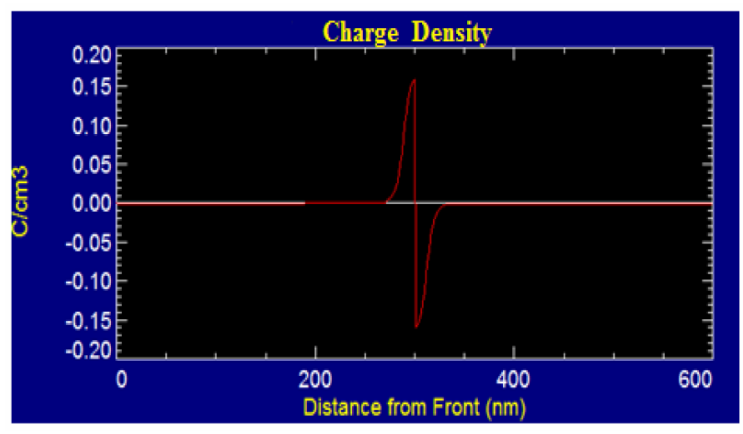

Figure 5. Charge density distribution in depletion region. one by one on the top surface of the solar cell. Varying the thickness of AR-coating from $5 \mathrm{~nm}$ to $100 \mathrm{~nm}$ and calculate the value of short circuit current and external efficiency of the solar cell. The variation of short circuit current of the GaAs solar cell with the thickness of the AR-coating for different materials is shown in Figure 9. Initially as we increase the thickness of AR-coating of $\mathrm{ZnO}$ the short circuit current increases very slowly up to $30 \mathrm{~nm}$ thicknesses. After the $30 \mathrm{~nm}$ thickness the short circuit current increases linearly with the thickness of AR-coating up to $55 \mathrm{~nm}$. After this thickness, the short circuit current gets to start saturated and achieved maximum value at $65 \mathrm{~nm}$ thickness. Similarly for AR-coating of $\mathrm{MgO}$, as we increase the thickness of AR-coating, the short circuit current increases very slowly up to $40 \mathrm{~nm}$. After the $40 \mathrm{~nm}$ thickness the short circuit current

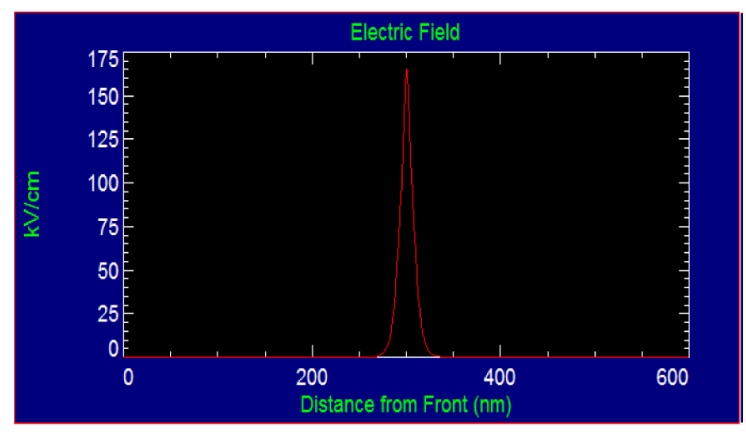

Figure 6. Electric field in depletion region of solar cell.

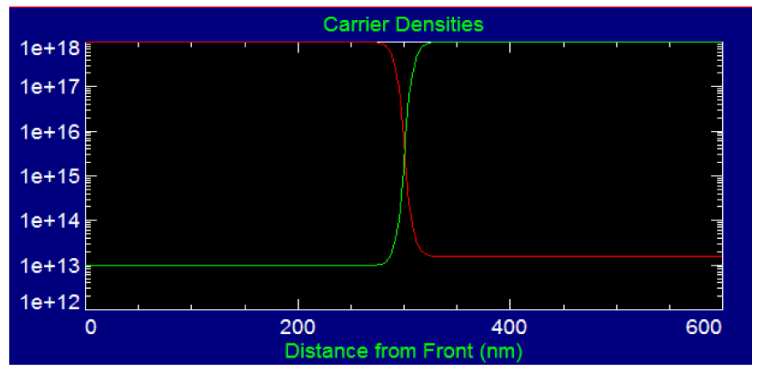

Figure 7. Carrier density in GaAs solar cell.

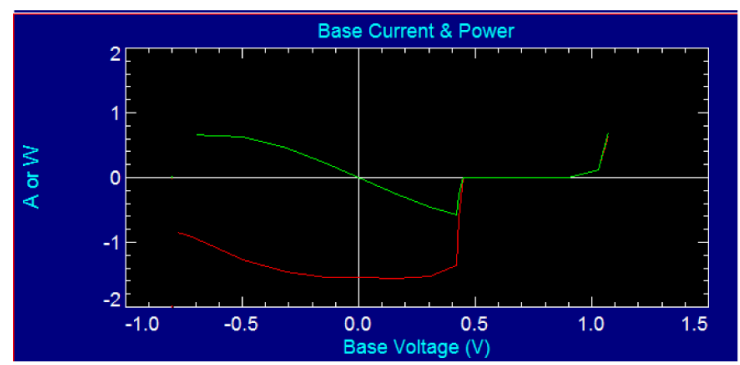

Figure 8. Voltage verses current \& power curve of solar cell without ARC. 
increases linearly with the thickness of AR-coating up to $70 \mathrm{~nm}$. After this thickness, the short circuit current gets to start saturated and achieved maximum value at $80 \mathrm{~nm}$ thickness. Once to achieve the maximum value, the short circuit current decreases very sharply with the increase in AR- coating thickness. The exact value of AR-coating thickness for maximum short circuit current and external efficiency with different materials of AR-coating is listed in Table 4.

The reason of slow increase in short circuit current up to $30 \mathrm{~nm}$ and $40 \mathrm{~nm}$ thickness for $\mathrm{ZnO}$ and $\mathrm{MgO}$ AR-coating respectively is that before this thickness AR-coating holds the condition of constructive interference more properly. Because the path difference between the light rays reflected from the top and bottom surface of the AR-coating is less than $\lambda / 4$. Therefore, up to this thickness AR-coating does not support properly to insert the light into the solar cell structure. After that as we increase the thickness of AR-coating, the reflectivity decreases linearly because AR-coating holds the condition of distructive interference more properly. At $65 \mathrm{~nm}$ thickness of $\mathrm{ZnO}$ film and $80 \mathrm{~nm}$ thickness of $\mathrm{MgO}$ film, AR-coating perfectly achieves the condition of distructive interference and shows the minimum reflectivity at this thickness. The variation of external efficiency of the solar cell with the thickness of the AR-coating for different materials is shown in Figure 10. The intensity of solar spectrum is high for the wavelength range from $550 \mathrm{~nm}$

Table 4. Best results of our optimization process

\begin{tabular}{lcccc}
\hline S. No. & materials & $\begin{array}{c}\text { Thickness of ARC Max. External } \\
(\mathbf{n m})\end{array}$ & Isc (A) \\
& & $6 f f i c i e n c y$ & \\
\hline 1. & $\mathrm{ZnO}$ & 65 & $67.49 \%$ & 2.819 \\
2. & $\mathrm{MgO}$ & 80 & $65.93 \%$ & 2.816 \\
\hline
\end{tabular}

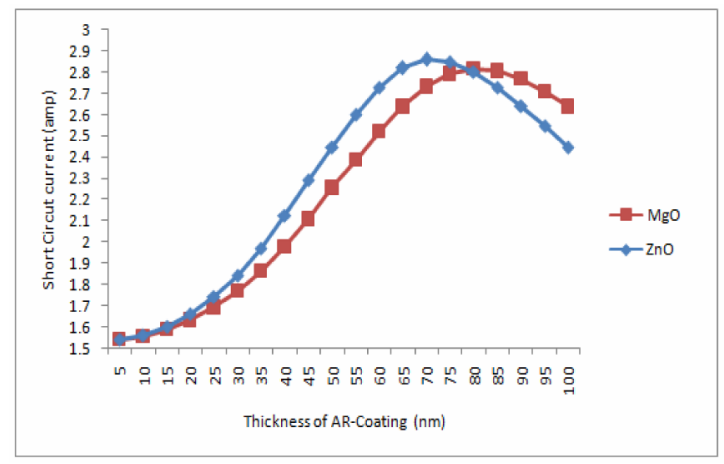

Figure 9. Variation of $\mathrm{I}_{\mathrm{SC}}$ with thickness of AR-coating. to $650 \mathrm{~nm}^{19}$. In this work we try to achieve minimum reflectivity of solar cell in that range. The variation of reflectivity of solar cell with the wavelength of solar spectrum for both $\mathrm{MgO}$ and $\mathrm{ZnO}$ film is shown in Figures 11 and 12 respectively.

\section{Conclusion}

The application of AR-coating on the front surface of the GaAs solar cell, gives us very encouraging results. The short circuit current is increased from 1.537A to $2.819 \mathrm{~A}$ at $65 \mathrm{~nm}$ thicknesses and 2.816A at $80 \mathrm{~nm}$ thicknesses for $\mathrm{ZnO}$ and $\mathrm{MgO}$ films respectively. The external efficiency

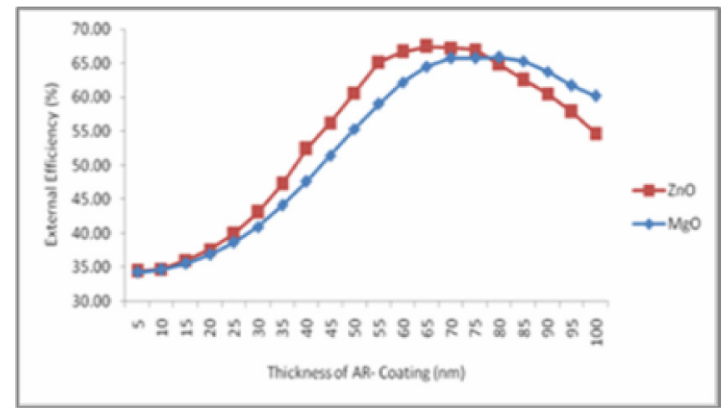

Figure 10. Variation of Extraction Efficiency with thickness of AR-coating.

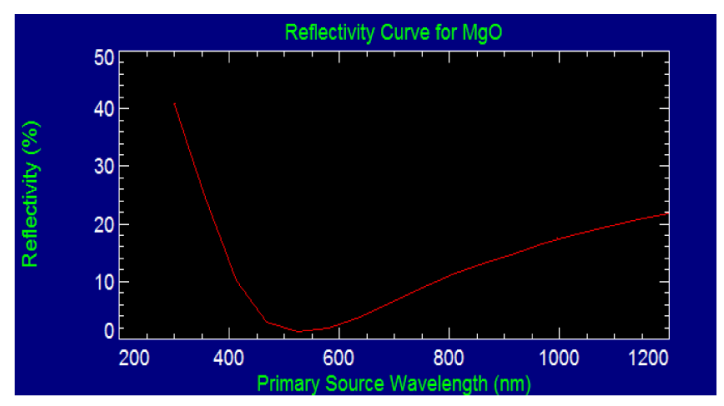

Figure 11. Reflectivity of Solar Cell for MgO AR-coating.

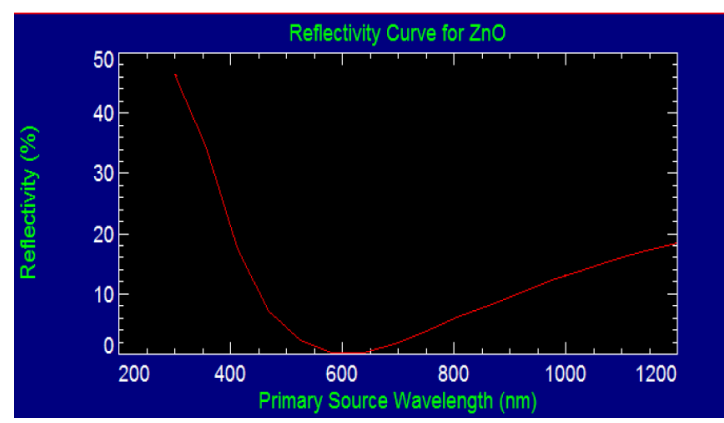

Figure 12. Reflectivity of Solar Cell for $\mathrm{ZnO}$ AR-coating. 
is increased by $33.09 \%$ for $\mathrm{ZnO}$ film and $31.53 \%$ for $\mathrm{MgO}$ film. This is because the reflectivity of solar cell for $\mathrm{ZnO}$ film is reduced up to $2 \%$ and for $\mathrm{MgO}$ the reflectivity is reduced up to $4 \%$ for the wavelength range from $550 \mathrm{~nm}$ to $650 \mathrm{~nm}$.

\section{References}

1. Martin AG. The path to $25 \%$ Silicon solar cell efficiency : history of silicon cell evolution, progress. Photovoltaics: Research and Applications. 2009; 17:183-9.

2. Emily DK, Jackson HA, James P, Albert P, Harry AA. Highly efficient GaAs solar cells by limiting light emission angle. Light Sci Appl. 2003; 2. doi:10.1038/Lsa.2013.1

3. Andenet A, Alex F, Nacer B, Chris B, Abdelhak B. Low temperature deposited boron nitride thin films for a robust anti-reflection coating of solar cell. Solar Energy Materials \& Solar Cells. 2010; 94:921-23.

4. Swatowska, Barbara, Stapinski, Tomasz, Drabczyk, Kazimierz; Panek, Piotr. The role of antireflective coatings in silicon solar cells- the influence on their electrical parameter. Optica Applicata. 2011; XLI(2).

5. Chakravarty BC, Vinod PN, Singh SN, Chakraborty BR. Design and Simulation of antireflection coating for application to silicon solar cell. Sol Energ Mater Sol Cell. 2002; 73(1):59-66.

6. Van Overstraeten RJ, Mertens RP. heavy doping effects in silicon, solid-state electronics. 1987:30(11); 1077-87.

7. Stapinski T, Swatowska B. A-Si:C:H and A-Si:N:H thin films obtained by pecvd for applicationsin silicon solar cells. J Electron Mater. 2008; 37(6):905-11.

8. Özgür Ü, Ya IA, Liu C, Teke A, Reshchikov MA, Doğan S, Avrutin V, Cho S-J et al. A comprehensive review of $\mathrm{ZnO}$ materials and device. J Appl Phys.2005; 98(4).
9. Taurian OE, Springborg M, Christensen NE. Self-consistent electronic structures of $\mathrm{MgO}$ and SrO. Solid State Comm. 1985; 55(4).

10. Robert E, Irving S, Malitson H. Index of refraction of magnesium oxide. J Res Natl Bur Stand. 1952; 49(4).

11. Jungkeun L, Takeshi K. J Lightwave Tech. 2000; 18(12):2158.

12. Rayner JT, Toomey DW, Onaka PM, Denault AJ, Stahlberger WE, Vacca WD. Cushing MC, Wang S. Spex: A mediumresolution 0.8-5.5 micron spectrograph and imager for the NASA Infrared Telescope Facilit. Publications of the Astronomical Society of the Pacific. 2003; 115:362.

13. Li L, Dobrowolski JA. High-performance thin-film polarizing beam splitter operating at angles greater than the critical angle. Appl Opt. 2000; 39(16):2754.

14. Sze SM. Semiconductor devices. 2nd edition. John Wiley \& Sons, Inc; 2002.

15. Kheraj VA, Panchal CJ, Desai MS, Potbhare V. Simulation of reflectivity spectrum for non-absorbing multilayer optical thin film. PRAMANA- Journal of Physics; 2009; 72(6):1011-22.

16. Macleod HA. Thin Film Optical Filters. 2nd edition. Chapter 3. Adam Hilger Ltd, Bristol; 1986.

17. Gupta S, Frankel MY, Valdmanis JA, Whitaker JF. Subpicosecond carrier llifetime in gaas grown by molecular beam epitaxy at low temperatures. Appl Phys Lett. 1991; 59(25):3276-78.

18. Michael B, Casimer D, Jay E, Vasudevan L, Guifang L, Carolyn M, Virendra M, Eric Van S. Handbook of Optics. 3rd edition. Mcgraw-Hill; 2009.

19. Bird RE, Hulstrom RL, Lewis LJ. Terrestrial solar spectral data sets. Solar Energy. 1983; 30:563. 